\title{
PSYCHO-SOCIAL IMPACT OF ORTHODONTIC TREATMENT IN ROMANIAN TEENAGERS AND YOUNG ADULTS
}

\author{
ANA MIHAILESCU ${ }^{1}$, ANCA LABUNET ${ }^{2}$, ALEXANDRINA MUNTEAN ${ }^{1}$, \\ ANDREEA KUI ${ }^{3}$, RADU SEPTIMIU CAMPIAN ${ }^{4}$
}

\author{
${ }^{1}$ Paedodontics Department, Iuliu Hatieganu University of Medicine and \\ Pharmacy, Cluj-Napoca, Romania \\ ${ }^{2}$ Dental Materials Department, Iuliu Hatieganu University of Medicine and \\ Pharmacy, Cluj-Napoca, Romania \\ ${ }^{3}$ Prosthodontics Department, Iuliu Hatieganu University of Medicine and \\ Pharmacy, Cluj-Napoca, Romania \\ ${ }^{4}$ Oral Rehabilitation, Iuliu Hatieganu University of Medicine and Pharmacy, \\ Cluj-Napoca, Romania
}

\begin{abstract}
Background and aims. This survey evaluated the psycho-social impact of oral health on the quality of life in Romanian teenage and young adult orthodontic patients.

Methods. Of the 300 standard questionnaires distributed in four dental offices, 125 questionnaires were returned. Each questionnaire contained 110 items, focusing on aspects like patients'satisfaction, self-confidence, school/work performances and aesthetic concern, in relation to oral health. The patients were 16-25 years of age and all were undergoing or had undergone orthodontic treatment in the previous two years. Data analysis was performed using the Statistical Package for the Social Science software (SPSS), version 19.0.

Results. $57.90 \%$ of the orthodontic patients participating in this study were happy about their dental status, 56.52\% declared themselves not shy because of their oral health issues, $52.33 \%$ considered themselves as attractive to other people, and 57.29\% replied (awarding a score between 8 and 10) that they were confident when smiling. Regarding self-confidence and school/work performances, 58\% of the participants declared they avoided speaking in public because of the aspect of their teeth and $47.42 \%$ considered that their school/work performances during the fix appliance therapy stayed the same as before appliance. Nevertheless, the selfperceived facial aspect improved during orthodontic treatment $(64.74 \%$ of replies had scores between 8 and 10 during the treatment versus $24.67 \%$ before the treatment). Several correlations were found between aspects such as psycho-social and functional variables, physical self-evaluation, and oral health issues.

Conclusion. Patients' satisfaction was improved during and after appliance therapy, for more than half of the participants. Self-confidence was low in relation to school/work performances; almost half of the patients reported stagnation in their school/work performances during the fix appliance therapy. However, more than 64\% of the patients participating in this study were quite satisfied about their facial aspect during and after the orthodontic treatment. Thus, the common concerns of the patients anxious about their aspect during appliance therapy are not supported by the findings of this study.
\end{abstract}

Keywords: orthodontic treatment, psycho-social impact, Romanian teenagers and young adults

Manuscript received: 27.10 .2017

Received in revised form: 13.03.2018

Accepted: 27.05.2018

Address for correspondence: sacuiana@yahoo.com 


\section{Background and aims}

The percentage of adult patients who received orthodontic treatment has increased significantly in the last decade [1]. More then 200,000 children and teenagers in England and Wales undergo treatment within the National Health Service every year, with growing numbers of adults and young people seeking treatment on a private basis [2]. In 2015, more than 1 million people in North America had braces [3]. The American Dental Association reported that $70 \%$ of braces were on females, and largely for aesthetics [3]. This observation is in agreement with that of Shaw [4] who, already in 1981, demonstrated that females were more dissatisfied with the appearance of their dentition and perceived a need for braces more often than males. The desire for orthodontic treatment could be explained not only by the fact that it improves the harmony of mouth and jaws, but also because once people can bite correctly, they can also eat more comfortably and care for their teeth and gums more easily; in addition, their smile will benefit immensely [2]. However, orthodontic patients experience pain and discomfort to a varying degree during the course of treatment [5]. In this respect, the patient-care concept has been recently introduced in healthcare systems; it focuses on the patient's experiences (during and after treatment) and satisfaction in relation to the quality of life [6]. Subjects with severe malocclusions may not report a negative impact on the quality of life, whereas others with minor irregularity report high negative impacts on the quality of life [6]. Therefore, the application of patientcentered measures such as oral health-related quality of life (OHRQoL) and self-esteem assessments in orthodontics are imperative to the study of treatment needs, outcome, and managing patient expectations [6].

While the quality of life, in general, refers to the individuals' perceptions of the positions in life in the context of the cultural and value system in which they live and in relation to their goals, expectations, standards and concerns [7], OHRQoL is a self-report specifically pertaining to oral health, capturing both the functional, social and psychological impacts of oral disease [8], more specifically a standard of health of oral and related tissues which enables an individual to eat, speak and socialize without active disease, discomfort, or embarrassment [9], the absence of negative impacts of oral conditions on social life or a positive sense of dentofacial self-confidence [10].

Several factors have been systematized after the 1980s with the purpose of evaluating the impact of the dento-maxillary anomalies on the psychological profile and social life of the individuals. Over the past two decades, patient satisfaction surveys have gained increasing attention as meaningful and essential sources of information for identifying gaps and developing an effective action plan for quality improvement in healthcare organizations [11]. However, there are very few published studies reporting the improvements resulting from feedback information of patient satisfaction surveys, and in most cases, these studies are contradictory in their findings [11].

The aim of this descriptive study was to evaluate the impact of orthodontic treatment on the quality of life, in Romanian teenagers and young adults, with emphasis on the psycho-social aspects.

\section{Materials and methods}

A survey was conducted on Romanian teenage and young adult orthodontic patients, questionnaires being distributed in the waiting rooms of four dental offices. The standardized questionnaire included 110 items on various aspects, similar to those from reference questionnaires e.g. global self-evaluation method, Dental Impact Profile, Oral Health Impact Profile, Oral Impacts on Daily Performances, Oral Health-Related Quality of Life, Child Oral HealthRelated Quality of Life and Child Oral Health Impact Profile. The questions are part of a larger questionnaire used to identify problems of orthodontic patients in ClujNapoca, Romania. The questionnaires were answered by the patients themselves or by the caregivers in case of children, and took about 10 minutes to complete; we present here the results on psychological and social impact, in terms of patient' satisfaction, self-confidence, school/ work performances and aesthetic concern. Patients were asked to reply by awarding a score (e.g. between 1 and 10 ), by answering with 'yes' or 'no', or by choosing the answer(s) from more statements provided.

Data analysis was performed using the Statistical Package for the Social Science software (SPSS) for Windows, version 19.0 (New York, USA). The correlations between aspects like psycho-social and functional variables, physical self-evaluation and oral health issues was assessed based on the Pearson correlation coefficients and significance values (i.e. Sig. [2-tailed]).

\section{Results}

A total of 300 questionnaires were applied to Romanian orthodontic patients 16-25 years of age. All patients had a removable or fixed appliance at the time of the survey (January-April, 2016) or had had orthodontic treatment in the 2 years previous to the survey. 125 questionnaires were returned; $71.4 \%$ of the respondents were females and $28.6 \%$ males, with a mean age of 21.14 years. They had been wearing the appliance for a mean interval of 12.4 months, ranging between 1 month and 5 years.

Patients were asked to evaluate some aspects related to oral health issues by awarding a number between 1 and 10. $57.90 \%$ rated their level of unhappiness due to dental problems between 1 (lowest level) and 4, 25.26\% rated this between 5 and 7 and only $16.85 \%$ between 8 and 10 (maximum level). These results suggest that most of the patients seemed fairly happy with regard to oral health. $56.52 \%$ of the patients included in the survey awarded a value between 1 and 4 to their shyness level due to dental 
problems, $23.91 \%$ of the patients awarded a value between 5 and 7 and only $19.56 \%$ awarded a value between 8 and 10 . In other words, more than half of the patients participating in our study were content with their public image and did not consider themselves shy because of their dental problems.

When asked to award a number between 1 (never) and 10 (always) to evaluate their self-perceived level of attractiveness and level of confidence when smiling, $52.33 \%$ of the respondents awarded a high score (between
8 and 10), and 15.11\% a low score (between 1 and 3 ) for the self-perceived level of attractiveness (Figure 1A). More than half of the patients (i.e. 57.29\%) declared a high selfconfidence when smiling, by awarding a score between 8 and 10 (Figure 1B).

The percentage of affirmative replies to the questions on the degree of self-confidence, and work/ school performances in relation to the aspect of patients' teeth are shown in Figure 2.
A.

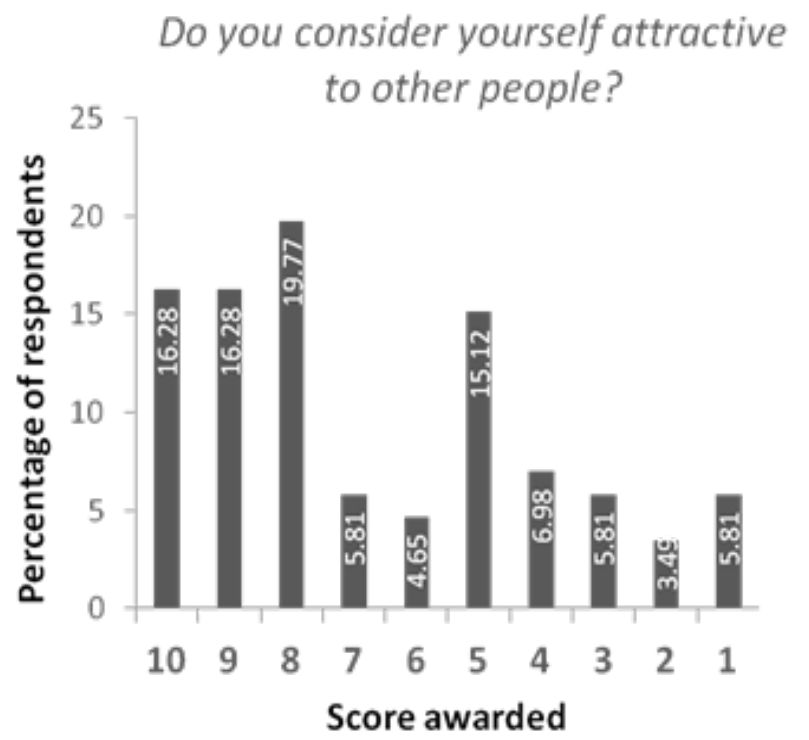

B.

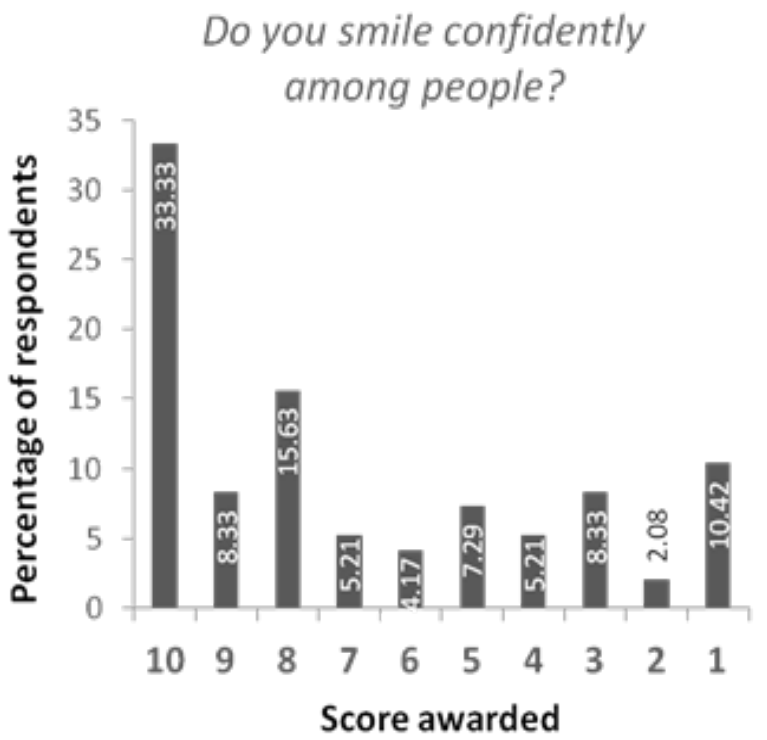

Figure 1. Score awarded by study participants to the item on self-perceived attractiveness to other people and self-perceived confidence when smiling in relation to participants' oral health. $(10=$ always; $1=$ never. $)$

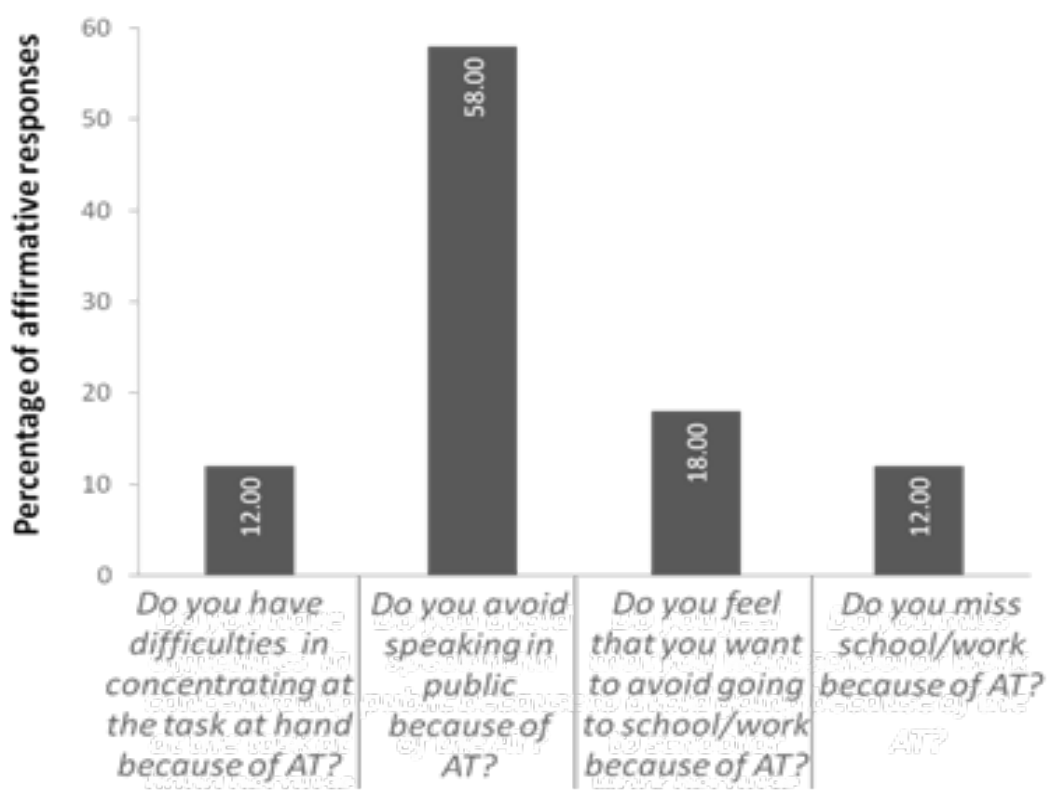

Figure 2. Percentage of respondents who replied affirmatively to the questions on self-confidence and school/work performances in relation to the aspect of their teeth. (AT = aspect of the teeth) 
More than half of the patients (i.e. 58\%) declared they avoided to speak in public because of the aspect of their teeth. This suggests a low self-confidence in what school/work performances related to the aspect of the teeth is concerned.

One item of the survey included a description of the social life, and asked the patient to choose one of the statements that best described this aspect. Of the total number of patients, $62.89 \%$ declared themselves as extroverted persons, who easily interacted with many people, $28.87 \%$ reported they had a few good friends that they met whenever they had time, $5.15 \%$ declared themselves as introverted persons who had but a few friends and 3.09\% stated they had no friends.

Patients were asked to evaluate their facial aspect by awarding a number between 1 (unsatisfactory) and 10 (very pleasant) before the appliance was set in place, during its use and after removal. Results before the placement of the appliance are presented in Figure 3A and results during orthodontic treatment in Figure 3B.

A.

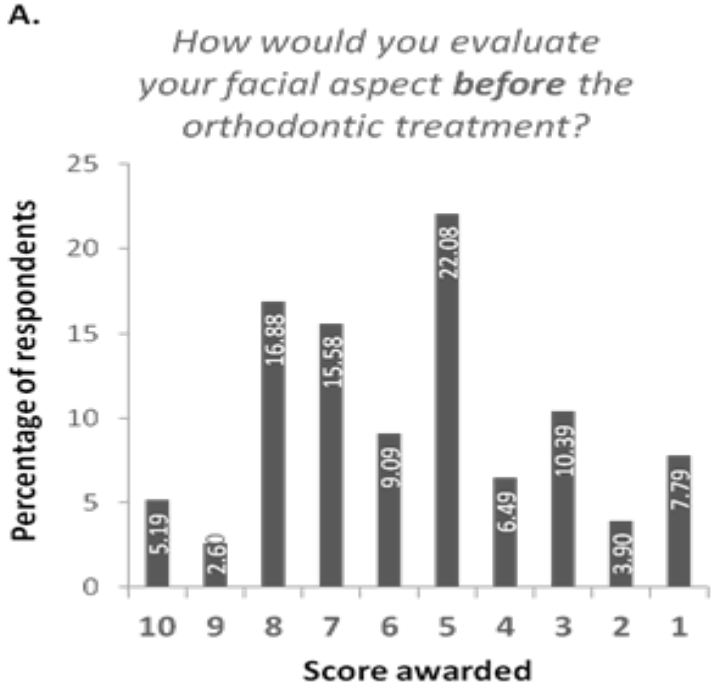

Of the total participants in this study, only $24.67 \%$ perceived their facial aspect as pleasant (score between 8 and 10) before the orthodontic treatment (Figure 3A), compared to $64.74 \%$ considered their facial aspect as pleasant (scores between 8 and 10) during the orthodontic treatment (Figure 3B). An increase (from 5.43 to 9.31) in the satisfaction level related to facial aspect was reported after the placement of the appliance and after removal, compared to the satisfaction level before the treatment.

When asked how the school or work performance had modified after beginning the orthodontic treatment with fixed appliances, $19.59 \%$ of patients answered that performances improved, $47.42 \%$ answered that they stayed the same, $2.06 \%$ stated that performances were reduced; the rest of the patients answered this question with "I don't know/I can't estimate". Respondents were requested to indicate their dental health issues by choosing one or several of the choices provided. Results are illustrated in Figure 4.

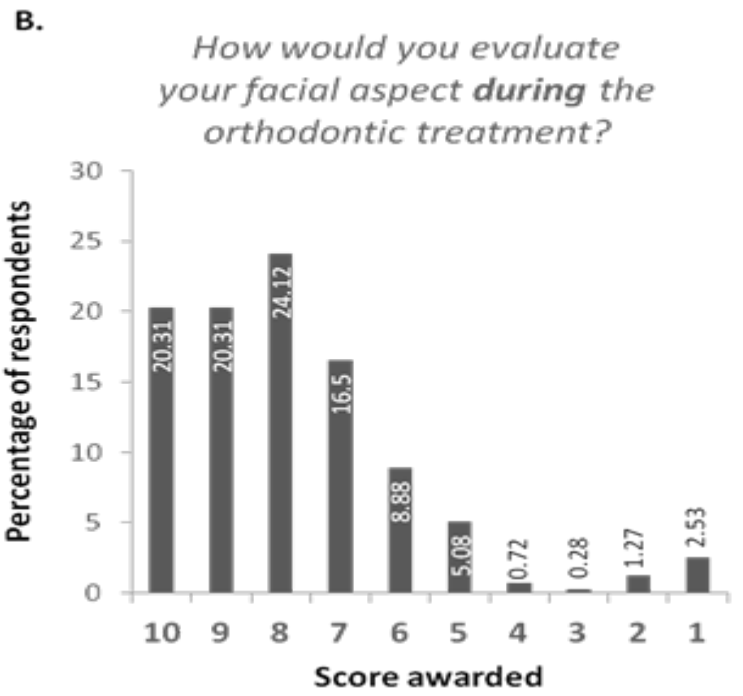

Figure 3. Score awarded by study participants to the item on self-evaluation of facial aspect, before and during the orthodontic treatment. $(10=$ very pleasant; 1 = unsatisfactory. $)$

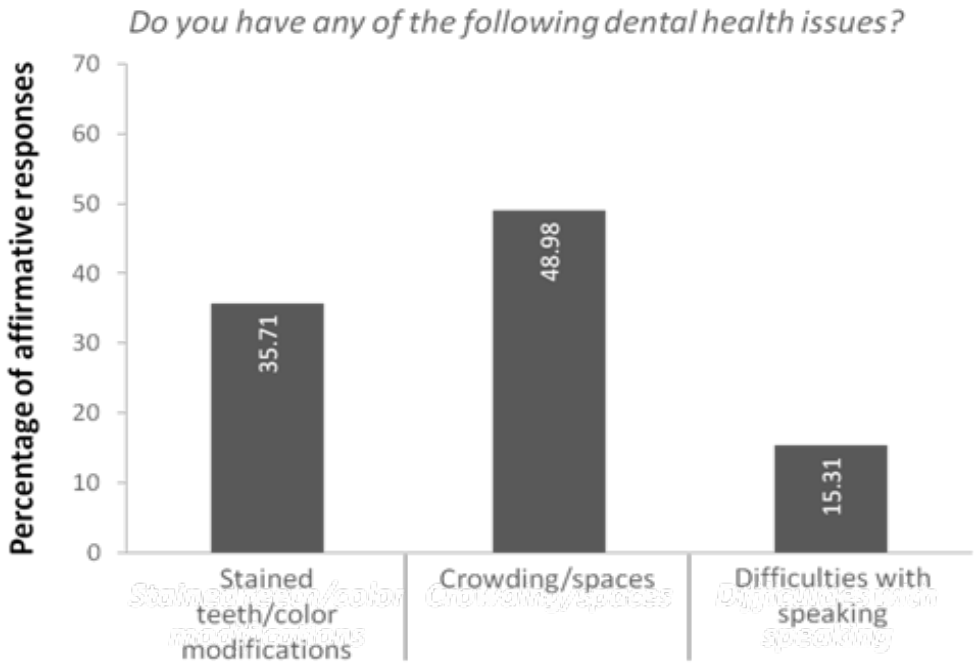

Figure 4. Dental health issues of the participants. 
Table I. Correlations between some psycho-social aspects and dental issues.

\begin{tabular}{|c|c|c|c|c|c|c|}
\hline & & \begin{tabular}{|l|}
$\begin{array}{l}\text { Concentration } \\
\text { problems }\end{array}$ \\
\end{tabular} & $\begin{array}{l}\begin{array}{l}\text { Mouth breathing / } \\
\text { snoring }\end{array} \\
\end{array}$ & $\begin{array}{l}\text { Dryness of the } \\
\text { mouth }\end{array}$ & $\begin{array}{l}\text { Difficult eating } \\
\text { hard food }\end{array}$ & Social life \\
\hline \multirow{3}{*}{$\begin{array}{l}\text { Concentration } \\
\text { problems }\end{array}$} & Pearson Correlation & 1 & -0.044 & 0.14 & 0.155 & $0.518 * *$ \\
\hline & Sig. (2-tailed) & - & 0.671 & 0.173 & 0.13 & 0 \\
\hline & $\mathrm{N}$ & 97 & 97 & 97 & 97 & 97 \\
\hline \multirow{3}{*}{$\begin{array}{l}\text { Mouth breathing / } \\
\text { snoring }\end{array}$} & Pearson Correlation & -0.044 & 1 & $0.420 * *$ & 0.02 & $0.482 * *$ \\
\hline & Sig. (2-tailed) & 0.671 & - & 0 & 0.847 & 0 \\
\hline & $\mathrm{N}$ & 97 & 97 & 97 & 97 & 97 \\
\hline \multirow{3}{*}{$\begin{array}{l}\text { Dryness of the } \\
\text { mouth }\end{array}$} & Pearson Correlation & 0.14 & 0.420 ** & 1 & $0.683 * *$ & $0.413^{* *}$ \\
\hline & Sig. (2-tailed) & 0.173 & 0 & - & 0 & 0 \\
\hline & $\mathrm{N}$ & 97 & 97 & 97 & 97 & 97 \\
\hline \multirow{3}{*}{$\begin{array}{l}\text { Difficult eating hard } \\
\text { food }\end{array}$} & Pearson Correlation & 0.155 & 0.02 & $0.683 * *$ & 1 & $0.257^{*}$ \\
\hline & Sig. (2-tailed) & 0.13 & 0.847 & 0 & - & 0.011 \\
\hline & $\mathrm{N}$ & 97 & 97 & 97 & 97 & 97 \\
\hline \multirow[t]{3}{*}{ Social life } & Pearson Correlation & $0.518 * *$ & $0.482 * *$ & $0.413 * *$ & $0.257^{*}$ & 1 \\
\hline & \begin{tabular}{|l|} 
Sig. (2-tailed) \\
\end{tabular} & 0 & 0 & 0 & 0.011 & - \\
\hline & $\mathrm{N}$ & 97 & 97 & 97 & 97 & 97 \\
\hline
\end{tabular}

* Correlation is significant at the 0.05 level (2-tailed); ** Correlation is significant at the 0.01 level $(2$-tailed). Sig. $=$ significance level; $\mathrm{N}=$ number of cases with non-missing values.

Correlations between aspects like psycho-social and functional variables, physical self-evaluation and oral health issues were investigated. "Crowded teeth or spaces between them" and "difficulties in speaking/pronouncing certain sounds" were weakly, positively correlated with "social life" ( $\mathrm{p}=0.000, \mathrm{P}=0.382$ and $\mathrm{p}=0.037, \mathrm{P}=0.212$, respectively). This may suggest that the happier respondents were with their social life, the weaker the chances that they had crowded or spaced teeth or difficulties with speaking. Positive correlations were found between "problems in concentrating on work/school duties because of the aspect of the teeth" and "bleeding of gums", "bad breath" and "dental pain". The highest concentration problems were observed for persons with a bad breath ( $\mathrm{p}=0.000, \mathrm{P}=0.354)$. Subjects who declared they had an attractive aspect seemed to have less dental pain, dryness of mouth and lips, and less difficulty in consuming harder foods. A weak, statistically significant correlation was found between "wearing or having worn an orthodontic appliance in the last 5 years" and "self-confidence after placement of the appliance" ( $\mathrm{p}=0.005, \mathrm{P}=0.284)$, which is in agreement with the results showing an increased selfconfidence when smiling after placement of the appliance. Other correlations summarized in Table I suggest that the more sociable the respondent was, less problems he/she had in concentrating because of dental problems.

\section{Discussion}

More than half of the patients included in this study were fairly happy with regard to dental problems. Considering the fact that they were or had been under orthodontic treatment when answering the questionnaire, this could possibly mean an improvement of their status during appliance therapy. Our survey results are in agreement with those obtained by Sheiham et al. [12] who observed that although many people experienced dental impacts, they rated their oral health as good and were satisfied with their dental status. As interpreted by Sheiham et al. [12], this means that a certain level of dental impacts is acceptable.

In terms of aesthetics, i.e. facial aspect selfevaluation, in our study, patients' satisfaction increased after the placement of the appliance and after removal compared to the satisfaction before appliance therapy. This finding suggests that the common concerns of patients who are anxious about their aspect during the treatment are not supported. Analyzing self-perceived facial aspect in relation to psychological impact, the results obtained in our study are also similar to those of Vaida et al. [13] who observed that the improvement of the patients' facial aspect at the end of the orthodontic treatment had a significantly positive correlation with the variables of global and social self-esteem. The study of Feu et al. [14] also showed a significantly improved aesthetic self-perception in orthodontic patients aged 12-15 years with fixed appliance.

Regarding self-confidence and school/work performances impacted by dental issues, our study finding - i.e. $58 \%$ of the orthodontic patients avoided speaking in public because the aspect of their teeth - is consistent with that of Sergl et al. [15] who found that patients' self-appreciation of dental aesthetics were predictive of the reported feeling of lack of confidence in public and oral constraint due to the fixed, functional or removable appliance wear.

Several studies concluded that patients with unattractive dentition are negatively affected on a psychosocial level and are more worried by their aesthetic aspect than patients with attractive dentition $[16,17]$. The OHRQoL is negatively affected, and deteriorates during orthodontic treatment, as shown also by previous studies like those of Johal et al. [18] in teenagers aged 13-15 years, Brosens et al. [19] in children/teenagers aged 11-16 years, O'Brien at al. [20] in children/teenagers aged 11- 
14 years, and Johal et al. [6] in adults with malocclusion. Nevertheless, there is evidence that self-esteem can be a protective factor in OHRQoL during orthodontic treatment [19], and that the level of self-esteem can significantly increase also as a result of the treatment [18]. Available research suggests that the most significant impact of malocclusion on the OHRQoL is psycho-social, rather than due to oral or functional problems [20]. This observation highlights how relative the concept of dental "disease" is. Its impact on the perception of well-being is not always of important negative consequence $[12,16]$. The impact of "disease" depends on several factors, such as patient expectations, preferences, resources and social and cultural values [16]. There are studies showing that certain patients are concerned by minor dental problems that affect their social life, while other patients do not show similar concern even in case of severe malocclusions, declaring themselves content with their aesthetical aspect $[6,17,20,21]$.

\section{Conclusions}

The patients' satisfaction was improved during and after appliance therapy, given that more than half of the orthodontic patients participating in the study were happy and not shy about their dental status, considered themselves as attractive to other people and were confident when smiling. However, when asked about self-confidence and school/work performances, more than half of the participants declared they avoided to speak in public because of their aspect of the teeth, which may suggest a low level of self-confidence. More than $47 \%$ of the patients included in this study did not consider that their school/work performances improved during the fix appliance therapy but rather stayed the same as before appliance. Nevertheless, the majority of the patients were satisfied about their facial aspect during and after the orthodontic treatment, and their self-perceived facial aspect improved during appliance therapy and after removal of the appliance. This finding proves that the common concerns of the patients anxious about their aspect during the treatment are unsupported. Although OHRQoL is usually deteriorated by psycho-social factors during the orthodontic treatment, the high overall and social self-esteem reflected in the patients' replies (e.g. for their self-perceived facial aspect, confidence when smiling, social life) can be a protective factor.

\section{References}

1. Gupta K, Saify M, Mahajan H, Jain DK, Gupta N. Orthodontic treatment considerations in pregnancy: an insight. J Orofac Res. 2012;2(2):91-94.

2. British Orthodontic Society. Why Orthodontics? London; 2014. Available from: https://www.bos.org.uk/Public-Patients/ Orthodontics-for-Adults/Why-Orthodontics

3. Johnson Elite Orthodontics. Orthodontic Statistics: Did You Know ...? Utah; 2015. Available from: http://www. johnsoneliteortho.com/orthodontic-statistics-did-you-know/ 4. Shaw WC. Factors influencing the desire for orthodontic treatment. Eur J Orthod. 1981;3(3):151-162.
5. Sergl HG, Klages U, Zentner A. Pain and discomfort during orthodontic treatment: causative factors and effects on compliance. Am J Orthod Dentofacial Orthop. 1998;114(6):684-691.

6. Johal A, Alyaqoobi I, Patel R, Cox S. The impact of orthodontic treatment on quality of life and self-esteem in adult patients. Eur J Orthod. 2015;37(3):233-237.

7. World Health Organization. Report of WHOQOL. Measuring Quality of Life. Geneva: WHO, Division of Mental Health and Prevention of Substance Abuse; 1997. Available from: http:// www.who.int/mental_health/media/68.pdf

8. Gift HC. Research directions in oral health promotion for older adults. J Dent Educ. 1992;56(9):626-631.

9. Department of Health. Choosing Better Oral Health. An oral health strategy for England. London: Department of Health, Dental and Ophthalmic Services Division; 2005 Nov 14. Available from: http:// webarchive.nationalarchives.gov.uk/20130124071526/http://www. dh.gov.uk/prod_consum_dh/groups/dh_digitalassets/@dh/@en/ documents/digitalasset/dh_4123253.pdf

10. Inglehart MR, Bagramian RA (eds.). Oral health-related quality of life: an introduction. In: Oral health-related quality of life. Chicago: Quintessence Publishing Co., Inc; 2002:1-6.

11. Al-Abri R, Al-Balushi A. Patient satisfaction survey as a tool towards quality improvement. Oman Med J. 2014;29(1):3-7.

12. Sheiham A, Cushing AM, Maizels J. The social impacts of dental disease. Proceedings; 1996 Jun 13-14; North Carolina. In: Slade GD (ed). Measuring oral health and quality of life. School of Dentistry, University of North Carolina; 1997:47-56. Available from: https://www.adelaide.edu.au/arcpoh/downloads/ publications/reports/miscellaneous/measuring-oral-health-andquality-of-life.pdf\#page $=58$

13. Vaida L, Pirte A, Corega C, Slăvescu D, Muţiu G. Correlations between the changes in patients' dental-facial morphology at the end of the orthodontic treatment and the psychological variables. Rom J Morphol Embryol. 2009;50(4):625-629.

14. Feu D, Oliveira BH, Celeste RK, Miguel JA. Influence of orthodontic treatment on adolescents' self-perceptions of esthetics. Am J Orthod Dentofacial Orthop. 2012;141(6):743-750. 15. Sergl HG, Klages U, Zentner A. Functional and social discomfort during orthodontic treatment--effects on compliance and prediction of patients' adaptation by personality variables. Eur J Orthod. 2000;22(3):307-315.

16. de Paula Júnior DF, Santos NC, da Silva ET, Nunes FM, Leles CR. Psychosocial impact of dental esthetics on quality of life in adolescents. Angle Orthod. 2009;79(6):1188-1193.

17. Mandall NA, McCord JF, Blinkhorn AS, Worthington HV, O'Brien KD. Perceived aesthetic impact of malocclusion and oral self-perceptions in 14-15-year-old Asian and Caucasian children in greater Manchester. Eur J Orthod. 2000;22(2):175-183.

18. Johal A, Cheung MY, Marcene W. The impact of two different malocclusion traits on quality of life. Br Dent J. 2007 Jan 27;202(2):E2.

19. Brosens V, Ghijselings I, Lemiere J, Fieuws S, Clijmans M, Willems G. Changes in oral health-related quality of life reports in children during orthodontic treatment and the possible role of self-esteem: a follow-up study. Eur J Orthod. 2014;36(2):186-191. 20. O'Brien C, Benson PE, Marshman Z. Evaluation of a quality of life measure for children with malocclusion. J Orthod. 2007;34(3):185-193.

21. Klages U, Bruckner A, Guld Y, Zentner A. Dental esthetics, orthodontic treatment, and oral-health attitudes in young adults. Am J Orthod Dentofacial Orthop. 2005;128(4):442-449. 